Article

\title{
Compression Shear Properties of Adhesively Bonded Single-Lap Joints of C/C Composite Materials at High Temperatures
}

\author{
Yanfeng Zhang ${ }^{1}$, Zhengong Zhou ${ }^{1, *}$ and Zhiyong Tan ${ }^{2}$ \\ 1 National Key Laboratory of Science and Technology on Advanced Composites in Special Environments, \\ Harbin Institute of Technology, Harbin 150000, China; zhangyanfenghit@126.com \\ 2 China Academy of Launch Vehicle Technology, Beijing 100076, China; doctortanzhiyong@126.com \\ * Correspondence: zyfztc@hit.edu.cn
}

Received: 28 October 2019; Accepted: 19 November 2019; Published: 22 November 2019

\begin{abstract}
The performance of joint structure is an important aspect of composite material design. In this study, we examined the compression shear bearing capacity of the adhesively bonded single-lap joint structure of high-temperature-resistant composite materials ( $\mathrm{C} / \mathrm{C}$ composite materials). The test pieces were produced in accordance with the appropriate ASTM C1292 standard, which were used for the compression shear test. The failure morphology of the layer was observed by a digital microscopic system and scanning electron microscope. The experimental result shows that the load on the test piece increased nonlinearly until the failure occurred, and most of the adhesive layer exhibited cohesive failures at three temperature points $\left(400,600\right.$, and $\left.800^{\circ} \mathrm{C}\right)$, while the interface failures occurred in a small part of the adhesive layer. A numerical analysis model was established using ABAQUS finite element software. The simulation results were compared with the test results to verify the correctness of the model. On the basis of correctness of the model verified by comparing the simulation results and the test results, the influences of temperature and overlapped length on the joint compression shear performance were studied through the validated simulation method. Numerical results showed that the ultimate load of the joint decreased with increases in temperature and that the distribution trends of the shear stresses in the overlapped length direction were substantially the same for joints of different overlapped lengths.
\end{abstract}

Keywords: compression shear properties; adhesively bonded single-lap joints; high temperature; $\mathrm{C} / \mathrm{C}$ composite materials; influencing factors

\section{Introduction}

The connection of composite parts is an important aspect in various fields ranging from materials to engineering structures [1]. In addition to the most common mechanical connections, the adhesive bonding of composite materials is a joint connection technique that uses adhesives to bond together composite components. Compared with traditional mechanical connections, the use of adhesive bonding technology for composite materials not only avoids the damage and stress [2] caused by punching on the components, but also enhances the integrity of the materials. Adhesive bonding technology enables the strength of the structure to be equal to or higher than that of traditional connections, which saves costs and reduces the weight of the bond. The structure of the adhesively bonded joint is simple, with good sealing performance, high specific strength, and low cost. It is widely used in the aerospace, mechanical manufacturing, and automobile fields [3,4]. More than 100 kinds of aircraft with adhesive structures exist around the world. The leading edge and nose cone of the B-58 supersonic bomber [5] are composed of carbon fiber reinforced composites, and the adhesive honeycomb structure is used widely for the bomber, replacing half a million rivets. 
Adhesively bonded joints nonetheless have some disadvantages due to their processing and associated overlapping. The bearing capacity of adhesively bonded joints is considerably affected by the manufacturing process, application environment, geometric dimensions, and the gap between adhesive layers. In particular, for bonded composite structures used in extreme environments such as high temperature and high humidity, joint strength presents an obvious dispersion. The strength of the adhesive changes with the temperature, resulting in changes in the bearing capacity of the joint. Although an adhesive layer has a strong shear capacity, its peeling resistance is poor. A reasonable structure should be designed based on the direction of the maximum load so that the joint can transfer the load as much as possible in the form of shearing. For example, in an adhesively bonded single-lap structure, the peeling stress at both ends of the adhesive layer increases due to secondary bending [6], resulting in failure of the adhesive layer. To reduce the torque generated by an eccentric load, the thin plate is usually selected as the adherend of an adhesively bonded single-lap structure. However, for materials with high brittleness such as $\mathrm{C} / \mathrm{C}$ composite materials and $\mathrm{C} / \mathrm{SiC}$ materials, the composite material undergoes brittle fracture if the adhesive strength is large when a thin plate is used for the single-lap joint. Therefore, in practical applications, a scarf joint [7] is used, or alternately the single-lap structure of brittle materials is reinforced along the thickness direction of the overlapped plate to fully take advantage of the shear performance of the adhesive. With the rapid development of the national defense industry, civil construction industry, automobile industry, and so on, the bearing capacity of the connection structure of high-temperature resistant composite materials must be increased.

Many reports have been published on the bearing capacity and failure modes of the adhesively bonded single-lap structures of composite materials. In-depth and extensive studies have been conducted on the factors influencing the properties of adhesively bonded structures of composite materials, such as thickness of the adhesive layer [8], gaps in the adhesive layers [9], temperature [10-12], and loading forms [13,14], and even reports on nanoscales have been produced $[15,16]$. The methods used have included experimental tests [17-19], finite element simulations [20,21], and analytical methods [22]. However, most objects employed in the research have been limited to the connection structures of resin-based fiber reinforced composite materials at temperatures below $400{ }^{\circ} \mathrm{C}$ [12]. Studies are lacking on the connection structures of high-temperature resistant materials ( $\mathrm{C} / \mathrm{C}$ composite materials and high-temperature ceramics) at a temperature resistance above $400{ }^{\circ} \mathrm{C}$ because (1) the connection technology of high-temperature-resistant composite materials involves military cutting-edge technologies with few published research results, and (2) because the preparation process of high-temperature-resistant composite materials is complicated [23] and expensive. Appropriate antioxidant measures should be taken as materials are oxidized easily at high temperatures [24,25]. These issues have posed challenges for the experimental study of connection structures of composite materials at high temperatures.

With support from the National Natural Science Foundation of China, we studied the compression shear properties of the adhesively bonded single-lap structures of high-temperature-resistant composite materials ( $\mathrm{C} / \mathrm{C}$ composite materials) at high temperatures by combining experimental tests and finite element simulations. Specifically, we examined the influences of ambient temperature, overlapped length, and gap position of adhesive layers on the joint bearing capacity.

\section{Materials and Methods}

\subsection{Specimen Materials}

\subsubsection{Adherend}

The material of the overlapped plate was $\mathrm{C} / \mathrm{C}$ piercing composite material. The $x y$ surface of the preform structure was a carbon fiber sheet woven from carbon fibers, which was stacked along the $z$ direction and reinforced by piercing carbon fiber. The stacked carbon fiber sheets were Toray T300-3K eight-heddle satin (Toray, Tokyo), and the fiber along the $z$ direction was Toray T300-1K (Toray, Tokyo) carbon fiber. The fiber spacing was $4.5 \mathrm{~mm}$. The $x, y$, and $z$ directions corresponded to the three main directions of the material, and the preform weaving mode and fiber direction are shown in Figure 1a. 
The performance of $\mathrm{C} / \mathrm{C}$ composites at different temperatures is shown in Table 1 . The preform was densified using the chemical vapor infiltration method (CVI) [26,27], then graphitized to form a kind of $\mathrm{C} / \mathrm{C}$ woven composite material. Because the $\mathrm{C} / \mathrm{C}$ composite materials were brittle, machining and water cutting would have caused a large amount of waste and low flatness. In this study, the required configuration was processed by wire cutting.
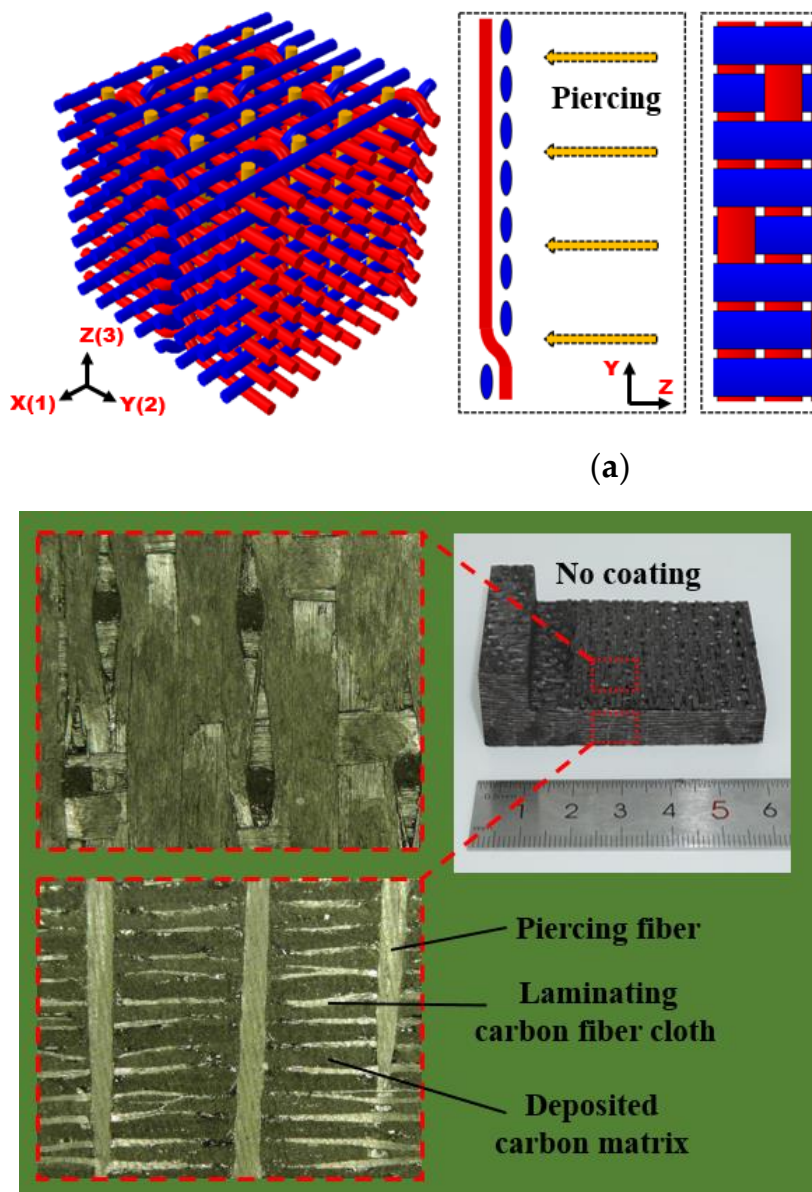

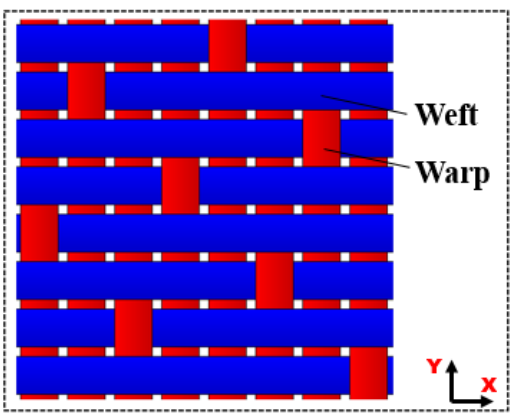

(a)
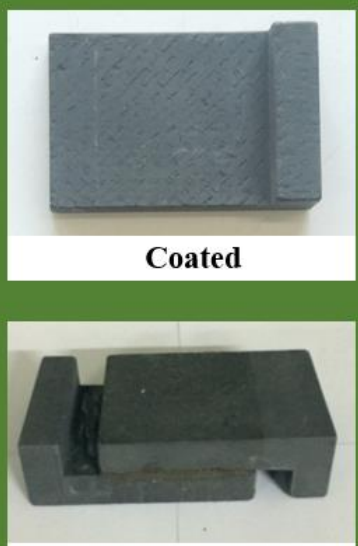

Specimen to be tested

(b)

Figure 1. (a) Preform weaving mode; (b) microscopic morphology of the materials and C/C plate before and after anti-oxidation treatment.

Table 1. Performance of the high-temperature resistant composite material $(\mathrm{C} / \mathrm{C})$ at different temperatures.

\begin{tabular}{|c|c|c|c|c|c|c|c|}
\hline \multirow{2}{*}{ Variable } & \multicolumn{3}{|c|}{ Temperature $\left({ }^{\circ} \mathrm{C}\right)$} & \multirow{2}{*}{ Variable } & \multicolumn{3}{|c|}{ Temperature $\left({ }^{\circ} \mathrm{C}\right)$} \\
\hline & 400 & 600 & 800 & & 400 & 600 & 800 \\
\hline Density $\left(\mathrm{g} / \mathrm{cm}^{3}\right)$ & & 1.65 & & Tensile strength $X_{t}(\mathrm{MPa})$ & 255 & 263 & 271.3 \\
\hline $\begin{array}{l}\text { Coefficient of thermal expansion } \\
\qquad\left(10^{-6}{ }^{\circ} \mathrm{C}\right)\end{array}$ & & 0.19 & & $\begin{array}{c}\text { Compression strength } X_{c} \\
(\mathrm{MPa})\end{array}$ & 200 & 212 & 224 \\
\hline Elastic modulus $E_{11}(\mathrm{GPa})$ & 90 & 92.5 & 95 & Tensile strength $Y_{t}(\mathrm{MPa})$ & 255 & 263 & 271.3 \\
\hline Elastic modulus $E_{22}(\mathrm{GPa})$ & 90 & 92.5 & 95 & $\begin{array}{l}\text { Compression strength } Y_{C} \\
(\mathrm{MPa})\end{array}$ & 200 & 212 & 224 \\
\hline Elastic modulus $E_{33}(\mathrm{GPa})$ & 15.5 & 13 & 10.3 & Tensile strength $Z_{t}$ (MPa) & 75.7 & 80.2 & 84.9 \\
\hline Shear modulus $G_{12}(\mathrm{GPa})$ & 23.8 & 25.7 & 27.6 & $\begin{array}{c}\text { Compression strength } Z_{C} \\
(\mathrm{MPa})\end{array}$ & 342 & 350 & 358 \\
\hline Shear modulus $G_{13}=G_{23}(\mathrm{GPa})$ & 5.4 & 6.1 & 6.8 & Shear strength $S_{12}(\mathrm{MPa})$ & 47.5 & 51 & 54.5 \\
\hline Poisson ratio $v_{12}$ & & 0.035 & & $\begin{array}{c}\text { Shear strength } S_{13}=S_{23} \\
(\mathrm{MPa})\end{array}$ & 14.6 & 16.4 & 18.2 \\
\hline Poisson ratio $v_{13}=v_{23}$ & & 0.032 & & & & & \\
\hline
\end{tabular}


Data [24] have shown that $\mathrm{C} / \mathrm{C}$ composite material is oxidized when the air temperature is higher than $400{ }^{\circ} \mathrm{C}$, and that the oxidation rate increases rapidly with increasing temperature. To prevent the test piece from being damaged, we used chemical vapor deposition (CVD) [28] to coat the surface of the $\mathrm{C} / \mathrm{C}$ composite material with a silicon carbide coating to obtain the antioxidant $\mathrm{C} / \mathrm{C}$ composite material required for the high-temperature test. The process parameters of CVI and CVD are listed in Table 2.

Table 2. The technical parameters of the chemical vapor infiltration method (CVI) and chemical vapor deposition (CVD).

\begin{tabular}{ccccc}
\hline Method & Equipment & Temperature $\left({ }^{\circ} \mathrm{C}\right)$ & Source Gas & Diluting Gas \\
\hline CVI & ZRHC-1500 CVD & $1000 \sim 1300$ & $\mathrm{C}_{2} \mathrm{H}_{2}$ & $\mathrm{Ar}$ \\
\cline { 3 - 5 } CVD & system & $673 \sim 1173$ & $\mathrm{CH}_{3} \mathrm{SiCl}_{3}$ & $\mathrm{Ar}$ \\
\hline
\end{tabular}

The overlapped plate was shaped into the letter L. Two C/C plates were assembled into one test piece through the single-lap joint. The microscopic morphology $\mathrm{C} / \mathrm{C}$ plate obtained by the digital microscopic system (KEYENCE VHX-7000, Japan, Osaka) and prepared test piece are shown in Figure $1 \mathrm{~b}$. The entire preparation process is shown in Figure 2. In accordance with the test piece configuration in the ASTM standards [29] and related literature [30,31] for material shear strength tests, we designed an adhesively bonded single-lap test piece of $\mathrm{C} / \mathrm{C}$ composite materials, as shown in Figure 3. The total length of the lap plate $(L t)$ was $60 \mathrm{~mm}$, the overlapping length $(L o)$ was $40 \mathrm{~mm}$, the thickness of the lap plate (Tp) was $10 \mathrm{~mm}$, the thickness of the adhesive (Ta) was $0.2 \mathrm{~mm}$, and the width of the adhesive $(W)$ was $40 \mathrm{~mm}$. Due to the high cost of $\mathrm{C} / \mathrm{C}$ composite materials and other constraints, three sets of test pieces were provided at each temperature point.

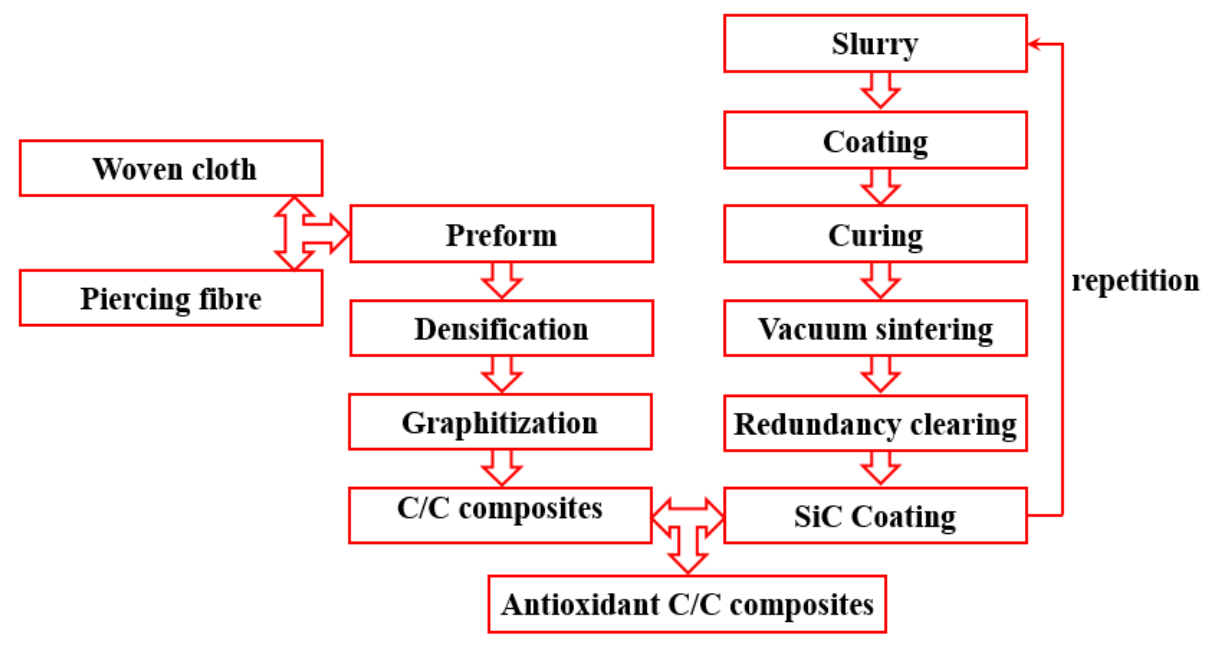

Figure 2. Preparation process of antioxidant $\mathrm{C} / \mathrm{C}$ composite materials.
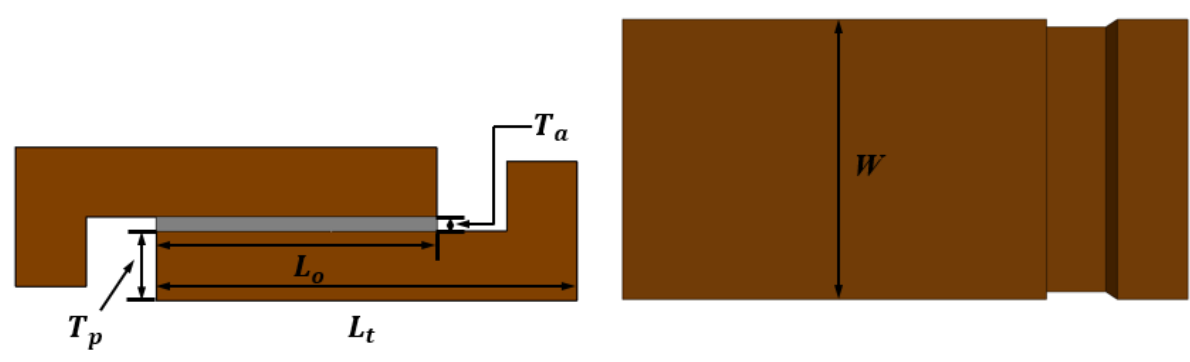

Figure 3. Geometric dimensions of the specimen. 


\subsubsection{Adhesive}

The adhesives used were high-temperature two-component adhesives developed by the Beijing Aerospace Research Institute of Materials and Processing Technology (Beijing, China). Component A was quartz fiber reinforced phenolic resin (synthetic with barium hydroxide as the catalyst), and Component $\mathrm{B}$ was aluminosilicate. The mass ratio was 1.5:1. Table 3 shows the material parameters of the adhesive at 400,600 , and $800{ }^{\circ} \mathrm{C}$. The inorganic filler silica aluminate was added to phenolic resin and the mixture was mixed evenly with the mixer (SXJB, YINYAN, Wuxi, China) and placed in the ultrasonic cleaner (PS-1010SMHT Hefei climbed Ultrasonic Technology Co., Ltd. Hefei, China) for $30 \mathrm{~min}$ of ultrasonic treatment to fully disperse the inorganic filler in the resin.

Table 3. Performance of the adhesive at different temperatures.

\begin{tabular}{ccccc}
\hline Temperature $\left({ }^{\circ} \mathrm{C}\right)$ & Elastic Modulus $E_{33}(\mathrm{GPa})$ & $\begin{array}{c}\text { Shear Modulus } \\
\boldsymbol{G}_{13} / \mathrm{G}_{23}(\mathrm{GPa})\end{array}$ & $\begin{array}{c}\text { Thermal Expansivity } \\
\left(\times \mathbf{1 0} \mathbf{0}^{-6} /{ }^{\circ} \mathrm{C}\right)\end{array}$ & $\begin{array}{c}\text { Working } \\
\text { Temperature }\left({ }^{\circ} \mathrm{C}\right)\end{array}$ \\
\hline 400 & 5.5 & 4.2 & & \multirow{2}{*}{-60 to 970} \\
\hline 600 & 4.8 & 3.7 & 4.2 & \\
\hline 800 & 4.0 & 3.7 & & \\
\hline
\end{tabular}

\subsubsection{Assembly}

Before bonding, the surface of the coated C/C plate was polished with sandpaper with a 100 particle size. The test piece was placed in an ultrasonic cleaner, and the surface of the lap plate was cleaned with acetone, washed with anhydrous ethanol, and dried. The thickness of the adhesive layer was controlled by the method shown in Figure 4. The test piece was placed in the center of a rectangular steel cover plate and surrounded by four steel bars, limiting the displacement of the adhesive layer during curing. Four steel blocks were placed at the four corners of the steel cover plate to adjust the thickness of the adhesive layer. The specific process of applying the adhesive was as follows: (1) Excess adhesive was evenly applied to the square bonding area at an appropriate speed to avoid excessive bubbles; (2) the test piece, steel bar, and steel block were placed as shown in Figure 4, and the upper cover plate was slowly laid flat; and (3) the test piece was carefully removed after excess adhesive was extruded from the bonding area. Excess adhesive was removed and the whole unit was placed into an electrothermal blowing dry box (101-2A, TAISITE, Tianjin, China) for curing. The curing condition of the high-temperature adhesive was set to $130^{\circ} \mathrm{C}$ for $2 \mathrm{~h}$. The temperature was raised from room temperature at a speed of $2-4{ }^{\circ} \mathrm{C} / \mathrm{min}$ to $130^{\circ} \mathrm{C}$. This temperature was maintained for $2 \mathrm{~h}$, then the heating was stopped. The bonded test piece was removed when it had naturally cooled for $8 \mathrm{~h}$ to room temperature.

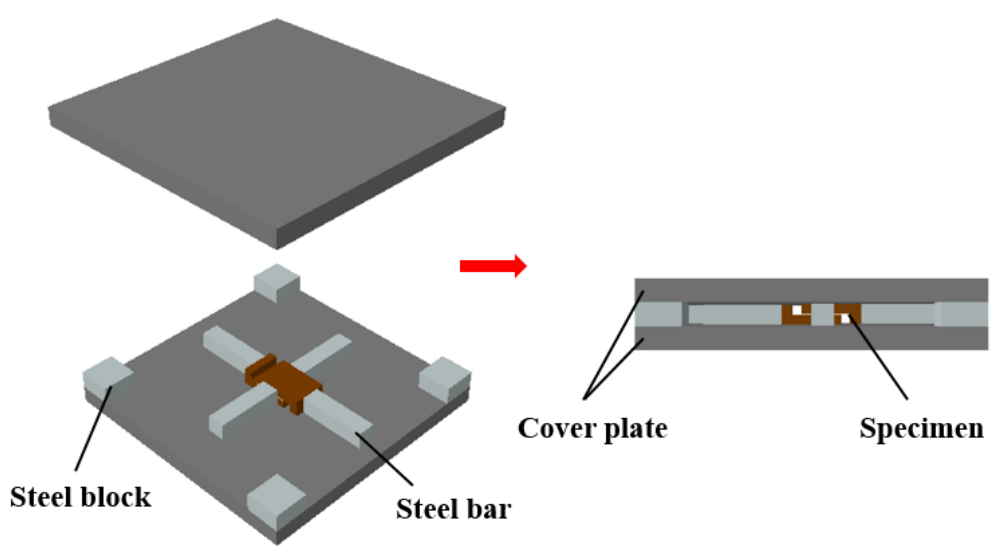

Figure 4. Adhesive thickness control method. 


\subsubsection{Fixture}

The test fixture was a pair of symmetric high-temperature alloy grooves. The two ends of the test piece were placed in the groove. The gap at the bottom of the groove was filled with metallic gaskets and fastened by bolts. During the loading, the fixture was fixed at one end and loaded at the other. The fixture and the loading method are shown in Figure 5.

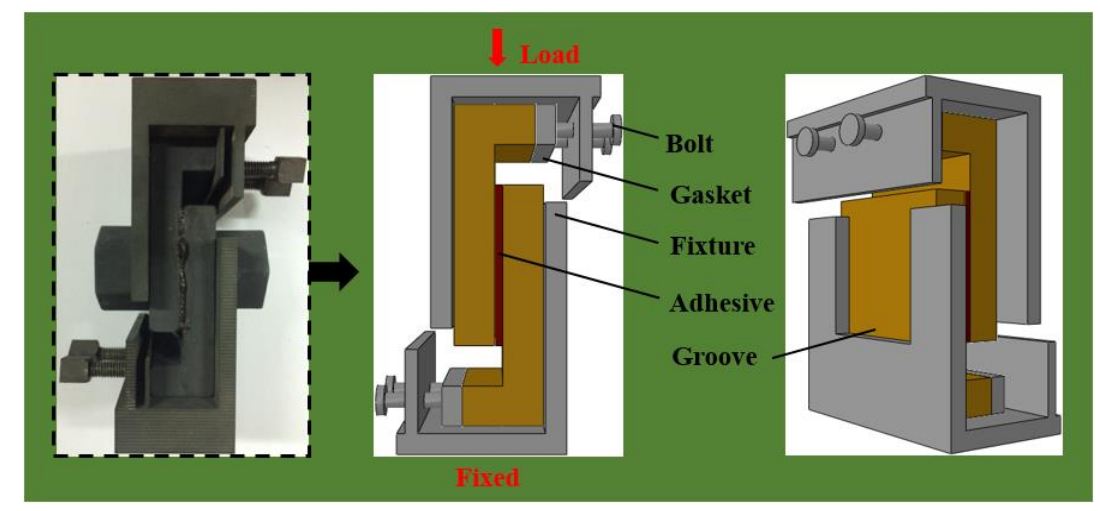

Figure 5. Fixture and loading method.

\subsection{Test Process}

The test equipment was a WDW-100 (SINGO Technology Co., Ltd. Hangzhou, China) microcomputer-controlled electronic universal testing machine equipped with a high-temperature test system and an automatic data acquisition and processing system with high test accuracy. The test was conducted under high-temperature, quasi-static, and compressive load conditions. The load was controlled by displacement. The test piece was loaded unidirectionally. The two ends of the fixture made contact with the upper and lower pressure plates to transmit the positive pressure. The test equipment and its internal structure are shown in Figure 6. During the test, the temperature of the high-temperature testing machine furnace was raised to the temperature required for the test $(400,600$, and $800^{\circ} \mathrm{C}$ ) for $10 \mathrm{~min}$ to ensure the evenness of the temperature inside the furnace. Then, the test piece was loaded at a loading rate of $0.5 \mathrm{~mm} / \mathrm{min}$.

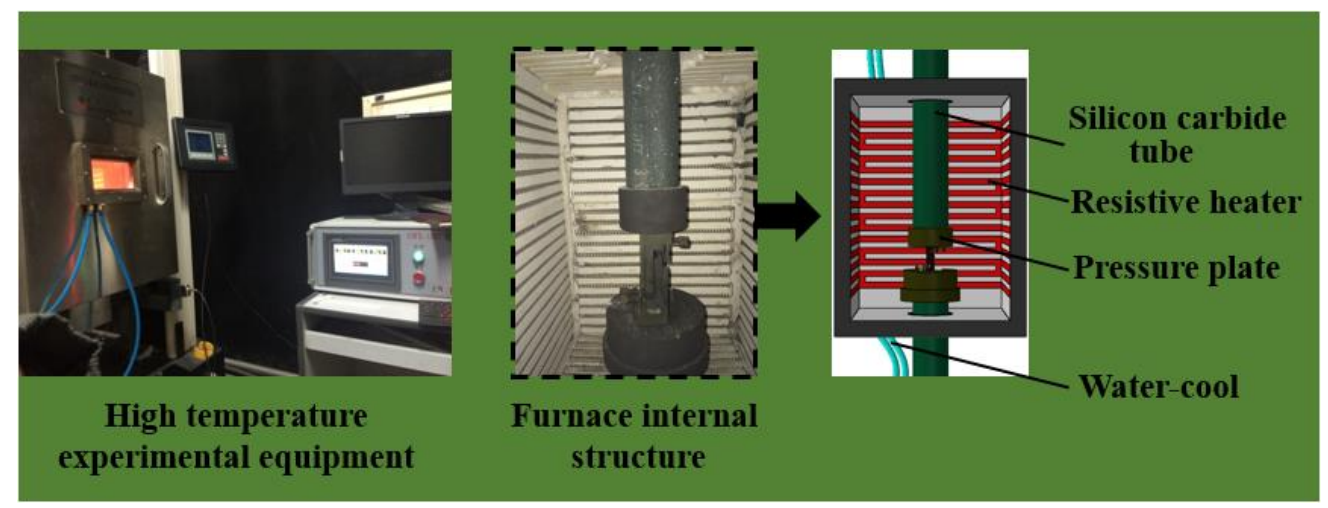

Figure 6. High-temperature test equipment and its internal structure.

\subsection{Finite Element Analysis}

To determine the influence of temperature, overlapped length, and the gap position of the adhesive layer on the compression shear performance of the adhesively bonded single-lap joint of $\mathrm{C} / \mathrm{C}$ composite materials, as well as to reduce costs, the finite element method was adopted to numerically simulate the above test process. The finite element calculation results were compared with the test results to verify the accuracy of the model. 


\subsubsection{Model Establishment}

For the above test process, the modeling was performed using ABAQUS 6.14 (France, Dassault) finite element software according to the geometric dimensions in Figure 3. The adhesively bonded joint model consisted of three parts, including two overlapped plates and an adhesive layer. A tie constraint existed between the overlapped plates and the adhesive layer, defining the different mesh densities of the overlapped plates and the adhesive layer. The adhesive layer was modeled using the cohesive element method [32]. The element type was COH3D8. In addition, the adhesive layer mesh was refined. A displacement load was applied to both ends of the model in the $x$ direction. The specific application method was to set the end in the negative $x$ direction as the fixed end, whereas the end in the positive $x$ direction was set as the load end. The constraints, meshing method, and boundary conditions are shown in Figure 7 . The fixture slightly deformed during the loading and was set as a rigid body. Two analysis sections were set up throughout the loading process. Firstly, a temperature load was applied to the model by using a predefined field. The initial temperature was room temperature, which was raised to the value required by the test $\left(400,600\right.$, and $\left.800{ }^{\circ} \mathrm{C}\right)$ and then the model was loaded.

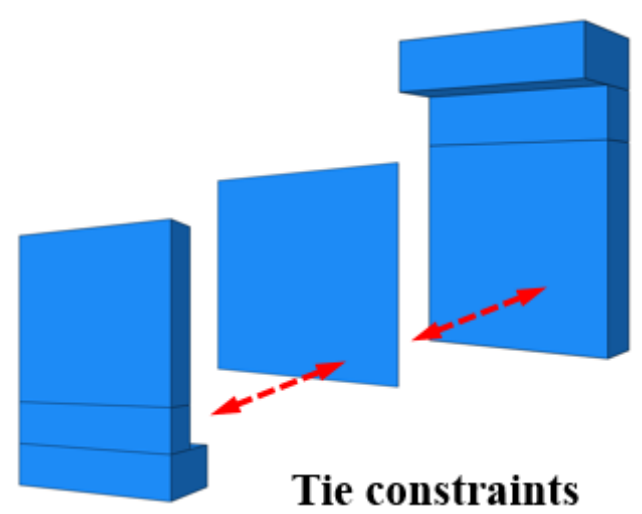

(a)

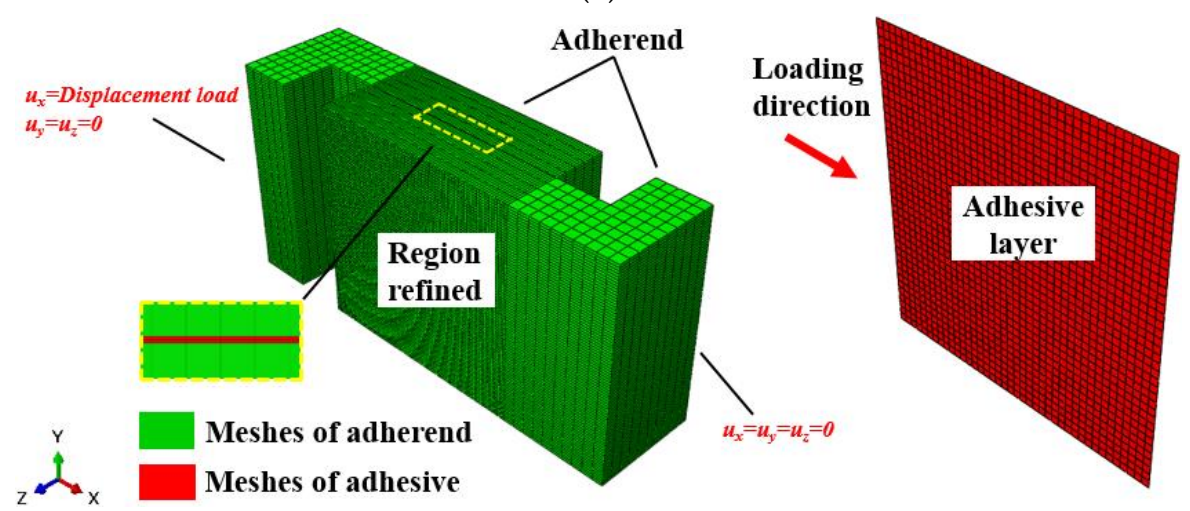

(b)

Figure 7. (a) Components and constraints; (b) mesh generation and boundary conditions.

\subsubsection{Failure Criteria}

The cohesion region model was constructed based on the stress-displacement constitutive relationship of the element, which was used to simulate the linear behavior of the element and the subsequent softening behaviors. The degree of stiffness degradation of the element was calculated until it was completely ineffective, a method that has been widely used in failure analysis [33]. In this study, the bilinear constitutive relation of the cohesive element was used to simulate the failure process of the adhesive layer. 
As shown in Figure 8, a bilinear constitutive relation assumes that the stress-displacement relationship of the element is linear before and after the strength of the material is reached. Where $\sigma_{n}$, $\sigma_{s}, \sigma_{t}$ indicate one normal component stress and two tangential component stresses of the element, $\delta_{n}$, $\delta_{s}$ and $\delta_{t}$ indicate one normal component stress and two tangential component displacements of the element, $\delta_{\text {element }}$ indicates the composition of the displacement of the element. Before the element was damaged, its constitutive relation could be expressed as

$$
\left[\begin{array}{c}
\sigma_{n} \\
\sigma_{s} \\
\sigma_{t}
\end{array}\right]=\operatorname{diag}\left(K_{n n}, K_{s s}, K_{t t}\right)\left[\begin{array}{c}
\varepsilon_{n} \\
\varepsilon_{s} \\
\varepsilon_{t}
\end{array}\right]
$$

where $\varepsilon_{n}, \varepsilon_{s}, \varepsilon_{t}$ indicate the corresponding normal component strain and two tangential component strains, respectively; and the stiffness matrix $K=\left[\begin{array}{lll}K_{n n} & K_{s s} & K_{t t}\end{array}\right]^{-1}$ is the element stiffness matrix. With increasing external load, the opening displacement of the element increased continuously. When the displacement was equal to the damage threshold ${ }_{-}{ }^{0}$, the stress value also reached the strength value $\delta^{\max }$ in this direction. At this time, the element started showing signs of damage and the material entered the softening section.

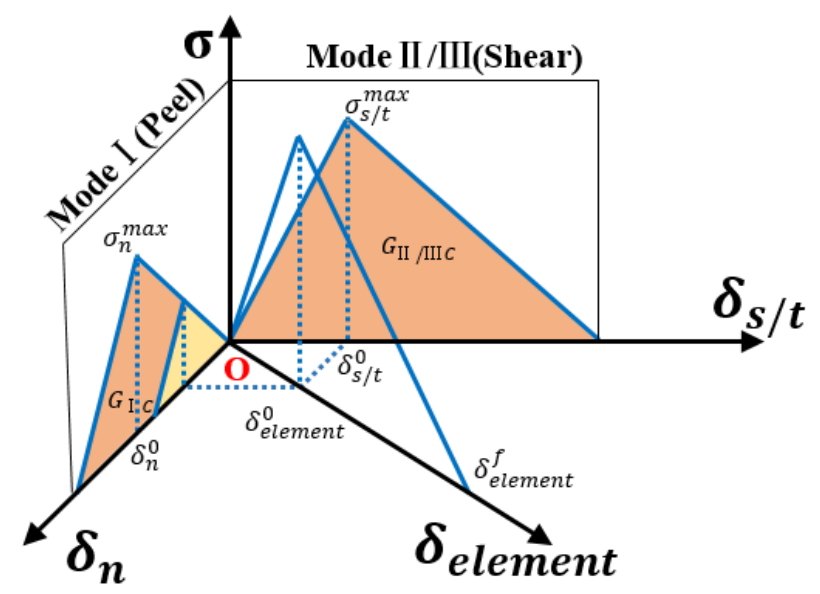

Figure 8. Mixed-mode traction relationship for cohesive elements.

ABAQUS provides several different initial damage criteria for the element. The experiment was conducted under a compression load so that the maximum stress perpendicular to the adhesive layer was compressive stress. The initial damage criteria employed in this study were

$$
\max \left\{\frac{\left\langle\sigma_{n}\right\rangle}{\sigma_{n}^{0}}, \frac{\sigma_{s}}{\sigma_{s}^{0}}, \frac{\sigma_{t}}{\sigma_{t}^{0}}\right\}=1,
$$

and no damage occurred when the peel stress was compressive stress, $\sigma_{n}=\left\{\begin{array}{cc}\sigma_{n} & \text { for } \sigma_{n}>0 \\ 0 & \text { for } \sigma_{n}<0\end{array}\right\}$, where $\sigma_{n}, \sigma_{s}, \sigma_{t}$ refer to the maximum nominal stress of the element in both directions according to the values shown in Table 4. Equation (2) indicates that when the maximum value of the nominal stress ratio in each direction of the cohesive element was equal to 1, damage began to occur. 
Table 4. Properties of cohesive interface elements.

\begin{tabular}{ccccc}
\hline Temperature $\left({ }^{\circ} \mathbf{C}\right)$ & $\sigma_{n}^{0}(\mathbf{M P a})$ & $\sigma_{s}^{0}$ and $\left.\sigma_{t}^{0} \mathbf{( M P a}\right)$ & $G_{I C}(\mathbf{N} / \mathbf{m m})$ & $\begin{array}{c}G_{I I C} \text { and } G_{\text {IIIC }} \\
\mathbf{( N / m m )}\end{array}$ \\
\hline 400 & 5 & 6.5 & 0.4 & 0.8 \\
\hline 600 & 4.4 & 5.8 & 0.3 & 0.6 \\
\hline 800 & 3.5 & 4.9 & 0.1 & 0.3 \\
\hline
\end{tabular}

In this study, damage evolution based on energy was adopted, and the criterion used for the completion of damage evolution was as follows:

$$
\left(\frac{G_{I}}{G_{I C}}\right)^{\alpha}+\left(\frac{G_{I I}}{G_{I I C}}\right)^{\alpha}+\left(\frac{G_{I I I}}{G_{I I I C}}\right)^{\alpha}=1
$$

where $G_{I C}, G_{I I C}$, and $G_{I I I C}$ indicate the normal critical energy release rate of the element and the shear critical energy release rate in both directions (Table 4). When it completely failed, the opening displacement of the element was equal to the ultimate displacement $\delta_{\text {element }}$ determined by the critical energy release rate $G_{C} . \alpha$ is equal to unity.

\section{Results and Discussion}

\subsection{Failure Analysis}

\subsubsection{Damage Mode}

At the initial stage of loading, no obvious sound was heard from the test piece, but the two plates suddenly separated when the load reached the breaking load, accompanied by an obvious cracking sound. This was a transient change process in which the connecting structure lost its bearing capacity. The breaking process was similar to brittle fracture. After the test piece cooled, the failure mode of the joint was observed using a digital microscopic system and a scanning electron microscope (FEI Helios Nanolab 600i), as shown in Figure 9. We found that the failure areas of the structure at the three temperature points were located on the bonding surface. Most of the adhesive layer exhibited cohesive failure (adhesives were observed on both overlapped plates after the failure). The interface failures occurred in a small part of the adhesive layer (adhesives were only found on one overlapped plate after the failure). The anti-oxidation coating on the outside of the overlapped plate at 400 and $600{ }^{\circ} \mathrm{C}$ presented no significant changes. The anti-oxidation coating on the outside of the overlapped plate was slightly shattered at $800^{\circ} \mathrm{C}$. The adhesive strength was the main factor affecting the shear strength of the connection structure. The test results show that most of the joint failure areas appeared inside the adhesive layer, indicating that the adhesive strength and antioxidant coating process should be further improved. 


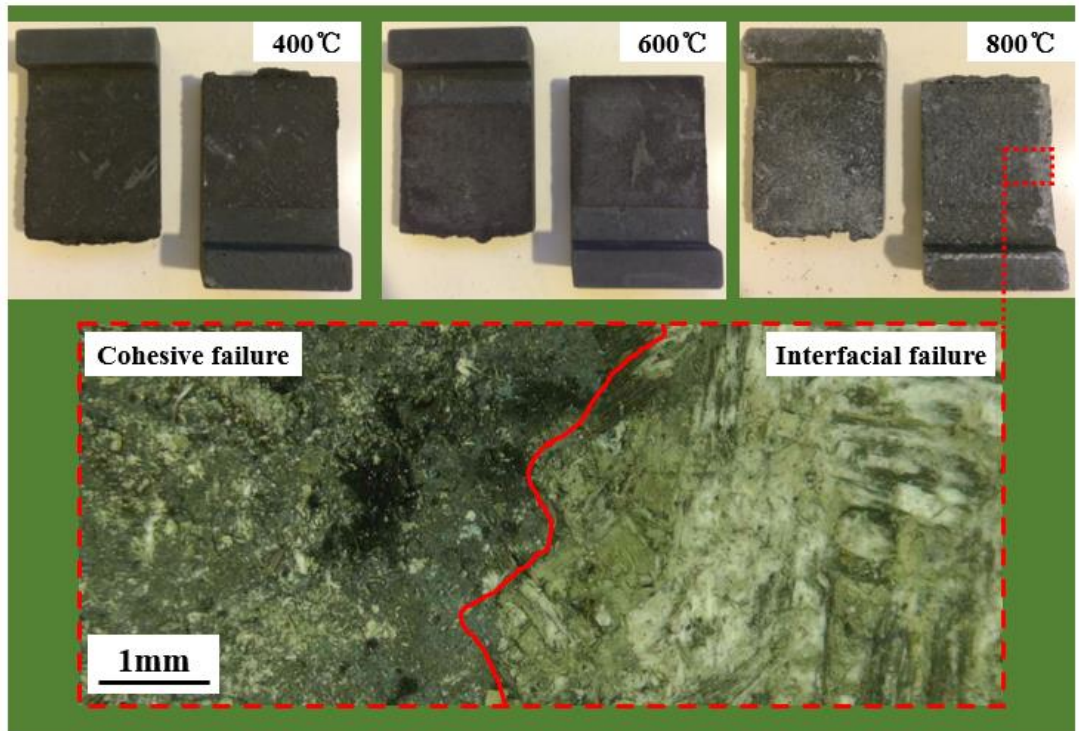

(a)

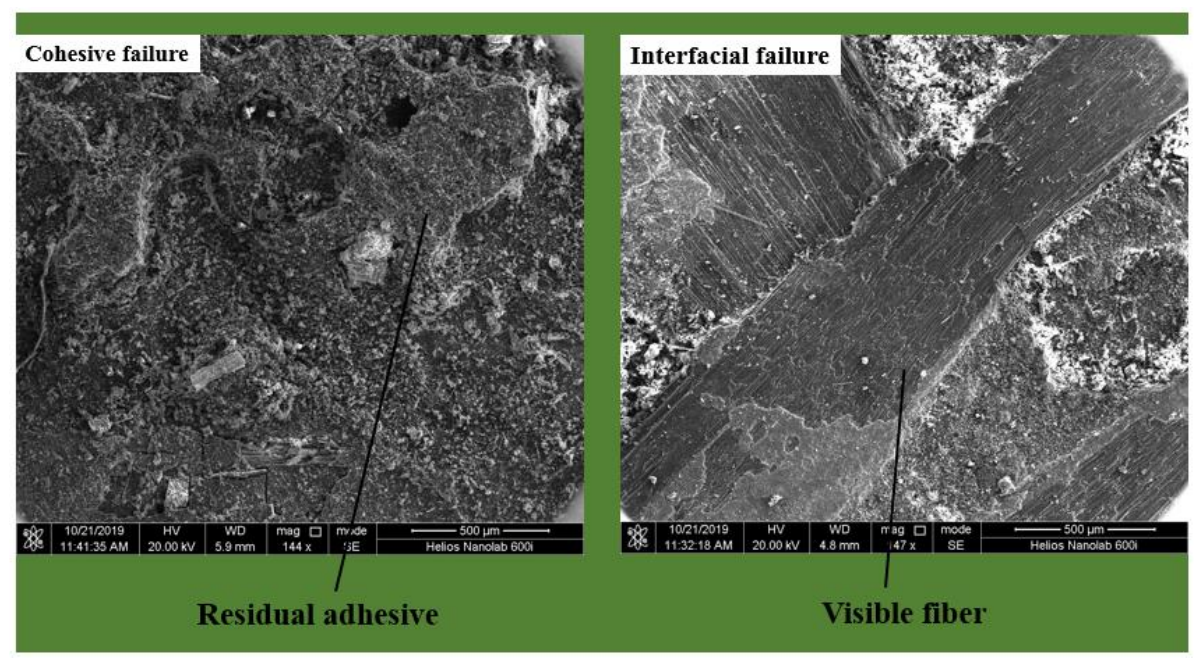

(b)

Figure 9. (a) Failure morphology observed by the digital microscopic system; (b) failure morphology observed by SEM.

\subsubsection{Comparison of Test Results and Finite Element Results}

The finite element model was established using the above method. The simulated load-displacement curves of the joint at three temperature points were calculated and compared with the test load-displacement curves. The result is shown in Figure 10. The load on the test piece increased nonlinearly until the failure occurred, mainly due to the nonlinear mechanical properties of the adhesive. After the ultimate load was reached, the load-bearing capacity dropped rapidly, the load value dropped to zero, and the curve presented as a falling straight line. We thus found that the ultimate load decreased with increasing temperature. There were two main reasons for this: the shear strength of the adhesive decreased with increasing temperature, and the increasing temperature loosened the joint antioxidant layer, resulting in slight oxidation of the $\mathrm{C} / \mathrm{C}$ plate. We simultaneously observed that the calculated ultimate load was slightly larger than the data measured in the test due to the uneven distribution of the thickness of the adhesive layer during the preparation of the test piece. We observed voids, such as pores in the curved adhesive layer and in the C/C composite materials, resulting in a decrease in the bearing capacity of the joint. These factors had not been fully considered 
in the simulation process. Despite these factors, the simulation results maintained good consistency with the test results, reflecting the bearing capacity and the failure process of the test piece.

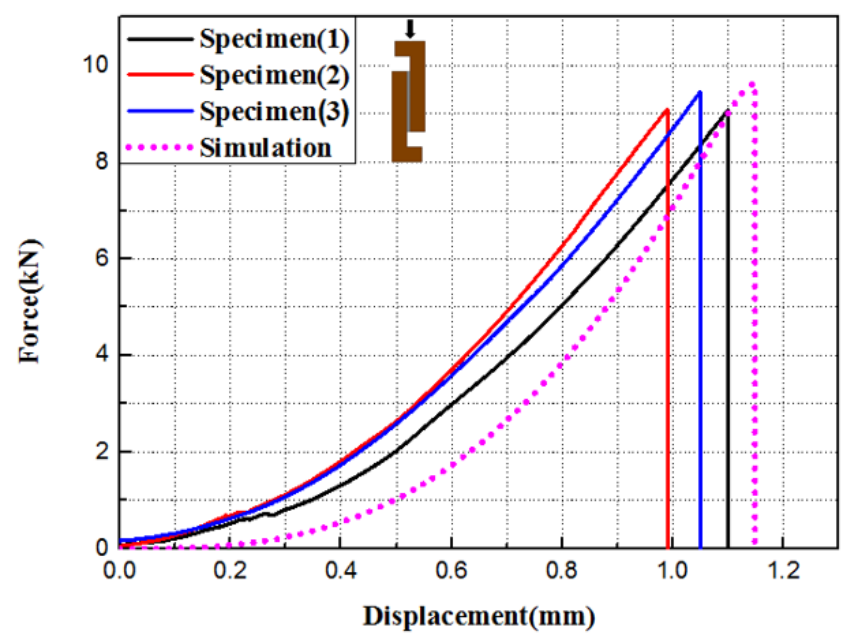

(a)

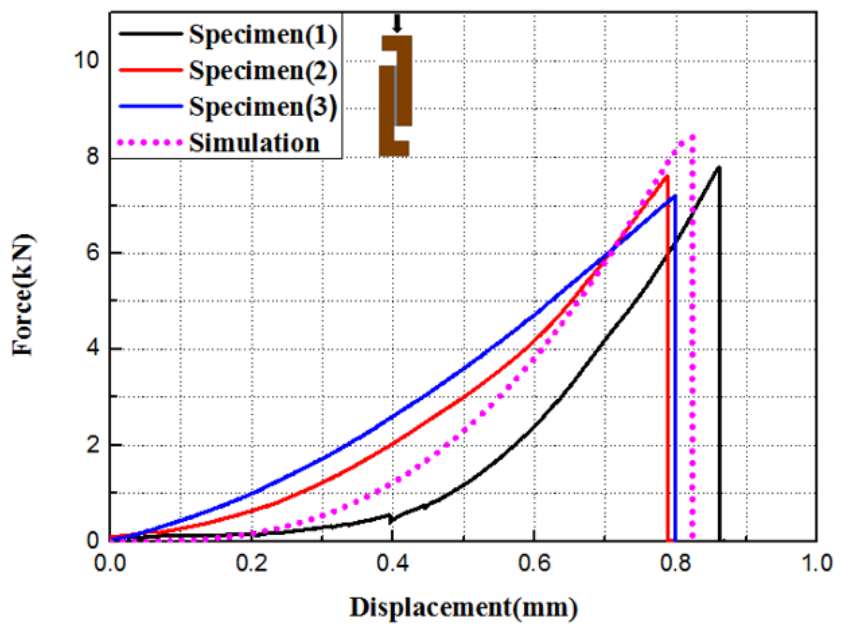

(b)

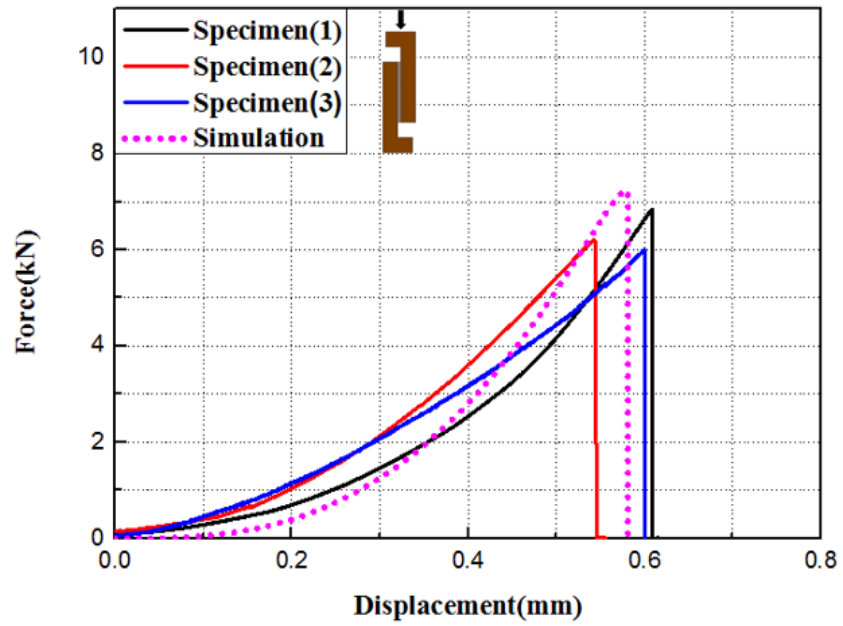

(c)

Figure 10. Single-lap joint compression shear load-displacement curve at (a) 400, (b) 600, and (c) $800{ }^{\circ} \mathrm{C}$. 


\subsubsection{Progressive Damage and Stress Distribution}

The bearing capacity of the adhesively bonded single-lap joint and the damage of the adhesive layer were closely related to the stress distribution of the adhesive layer. The stress of the adhesive layer was compound stress composed of shear stress parallel to the bonding surface and peeling stress perpendicular to the bonding surface. The peeling stress was generated by the secondary bending caused by the load deviating from the axis of the sample. The fixture structure in this study limited the rotation of the joint, considerably reducing the value of the peeling stress. Therefore, the stress distribution of the adhesive layer should be mainly determined by the shear stress.

Taking the center point of the adhesive layer as the coordinate origin and the loading direction as the $x$ axis, the coordinate system was established, as shown in Figure 11a. Take the four points A, B, $\mathrm{C}$, and $\mathrm{D}$ in the joint-loading process, in point $\mathrm{A}$ is the shear stress of the adhesive layer to reach the adhesive shear strength, which is the initial point of the damage, and point $\mathrm{D}$ is the failure load point. Figure $11 \mathrm{~b}$ shows the normalized shear stress of the adhesive layer corresponding to each point at $400{ }^{\circ} \mathrm{C}$. Figure 12 depicts the stress distribution and progressive damage corresponding to each point at $400{ }^{\circ} \mathrm{C}$. The shear stress distribution was substantially symmetrical along the overlapped length of the joint. The shear stress distribution was relatively even in most areas near the middle, the gradient value was small, and the shear stress increased from the middle to the two edges, which reached a peak at the edge and produced a significant stress concentration. The edges of adhesive layer were also the initial point of the fracture. As the load increased, the edge stress value decayed and the stress peak moved from the two sides to the middle. Corresponding to the shear stress distribution, the damage evolution process of the adhesive layer was also distributed symmetrically. The failure region expanded from the edge of the adhesive layer to the center. The maximum peeling stress appeared at the edge of the adhesive layer, which was compressive stress and not the primary cause of joint failure.

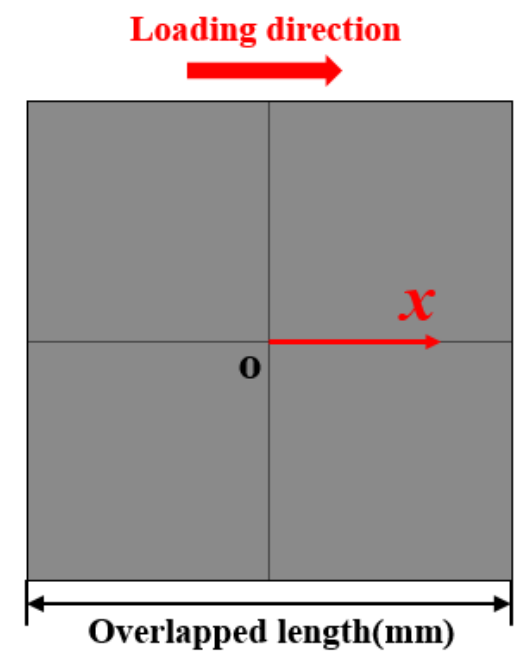

(a)

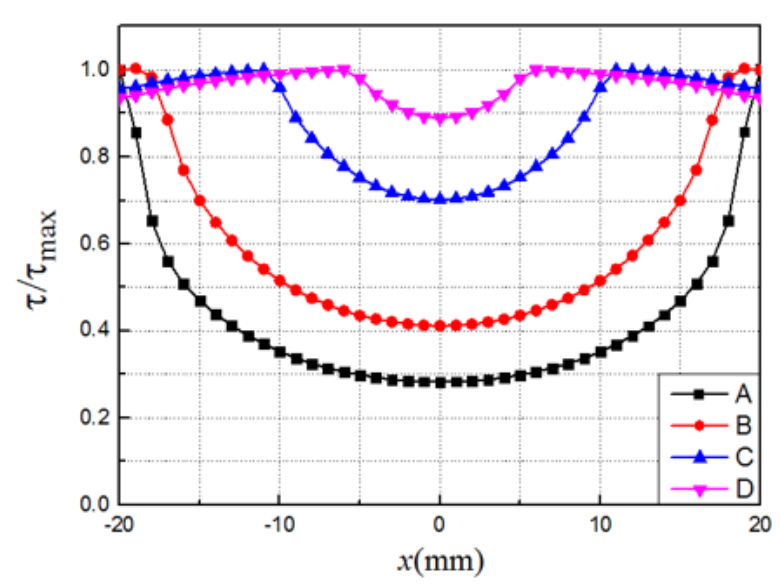

(b)

Figure 11. Distribution of adhesive layer shear stress along the overlapped length: (a) establishment of the coordinate system and (b) normalized shear stress of each loading point adhesive. 


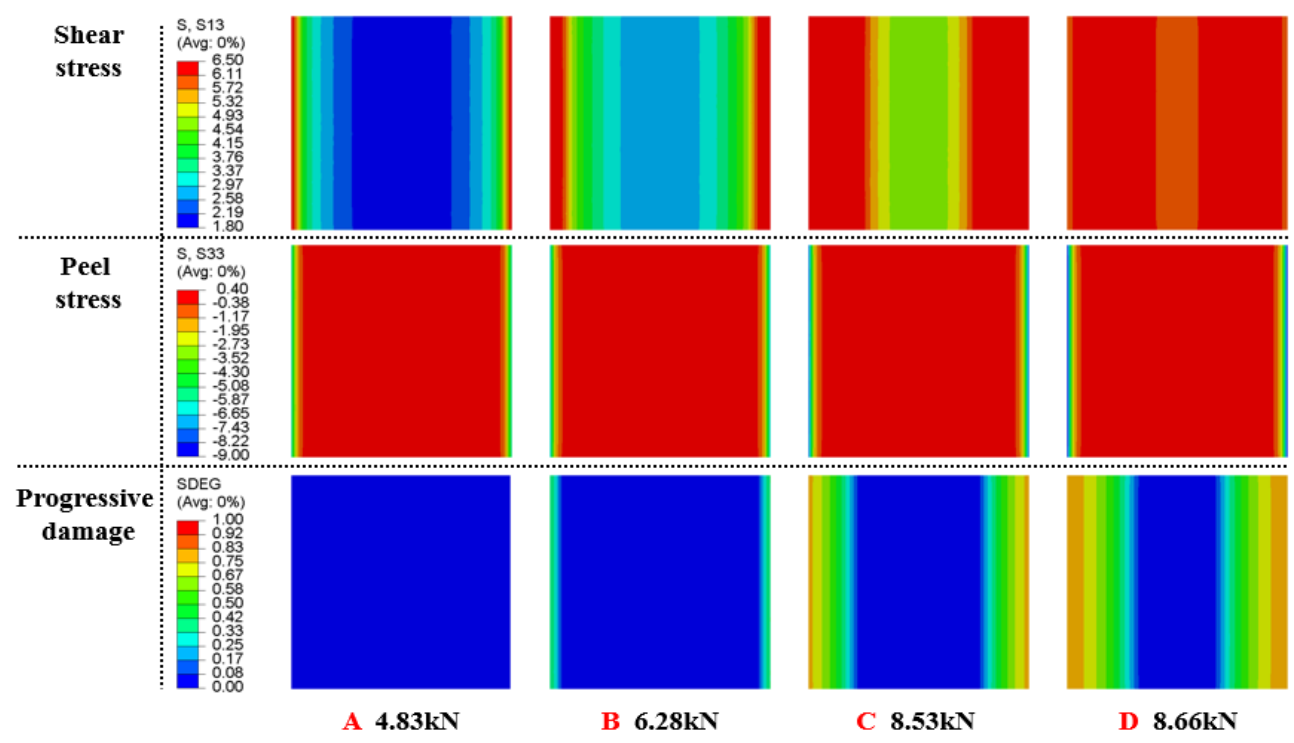

Figure 12. Stress distribution and progressive damage at $400{ }^{\circ} \mathrm{C}$.

\subsection{Influencing Factors}

We analyzed the failure modes, damage processes, and shear stress distributions of the adhesively bonded single-lap joints of $\mathrm{C} / \mathrm{C}$ composite materials with fixed geometric parameters at three temperature points in this study. The test results and simulation results were also compared. In actual engineering, different configurations of glue joints are often applied at different temperatures to satisfy the needs of various scenarios $[34,35]$. In this investigation, the above modeling method was used to study the influences of temperature, overlapped length, and the gap position of the adhesive layer on the joint compression shear mechanical properties.

\subsubsection{Temperature}

Six temperature points were selected for the tests, including a room temperature (RT) and 200, $400,600,800$, and $1000^{\circ} \mathrm{C}$. Figure 13 shows the variations in the ultimate joint load at each temperature point. The ultimate load of the joint decreased with increasing temperature. There were two reasons for this: different values of critical shear traction were used at different temperatures, and the elastic modulus of the $\mathrm{C} / \mathrm{C}$ plate increased with increasing temperature, which reduced the ductility of the plate, thereby reducing the bearing capacity of the structure. The gradient of the load gradually enlarged, and the load value presented nonlinear variation along with the temperature changes.

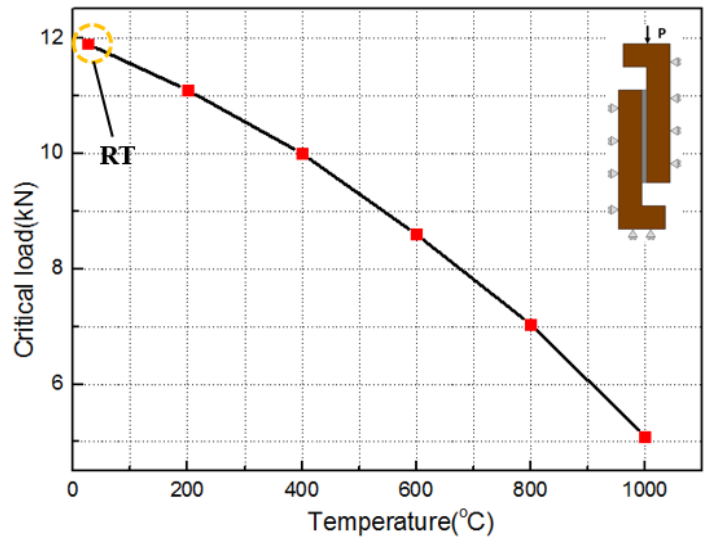

Figure 13. Ultimate load changes with temperature changes. 


\subsubsection{Overlapped Length}

The overlapped length directly affects the ultimate load of the joint. The ultimate load is proportional to the overlapped length. The variation law of the shear stress distribution of the adhesive layer with the overlapped length was then modeled. The overlapped length was 30-50 mm (with an interval of $5 \mathrm{~mm}$ ). Figure 14 shows the distribution curve of the normalized shear stress of the adhesive layer element when the joint adhesive layers of different overlap lengths reached the failure strength at $400{ }^{\circ} \mathrm{C}$. For joints of different overlapped lengths, the distribution trends of the shear stresses in the overlapped length direction were substantially the same. As the overlapped length increased, the corresponding minimum shear stress gradually decreased.

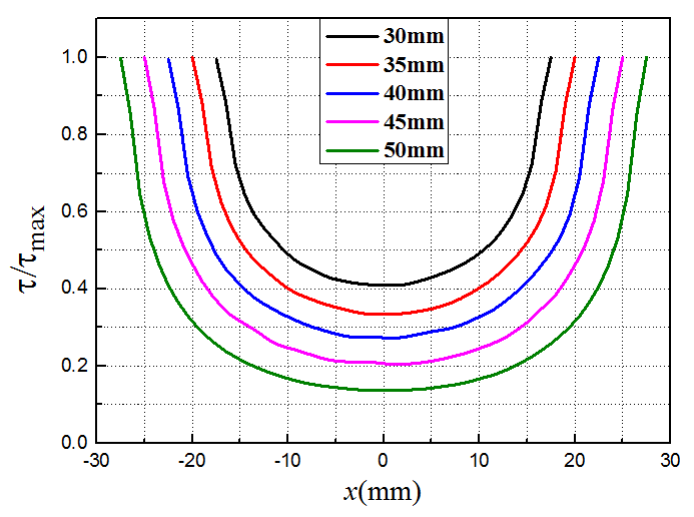

Figure 14. Normalized shear stress distribution of the joint adhesive layer with different overlapped lengths at $400{ }^{\circ} \mathrm{C}$.

\section{Conclusions}

In this study, we examined the compression shear properties of the adhesively bonded single-lap joints of $\mathrm{C} / \mathrm{C}$ composite materials at high temperatures. Failure modes and mechanisms of joints were described and the effects of temperature and the overlapped length on the joint compression shear performance were determined through the validated simulation method. Some conclusions derived from the experimental and numerical studies can be summarized as follows:

(1) At high temperatures $\left(400,600\right.$, and $\left.800{ }^{\circ} \mathrm{C}\right)$, the adhesively bonded single-lap joints of $\mathrm{C} / \mathrm{C}$ composite materials under the compression load exhibited shear failures on the bonding surface. By observing the failure modes with a digital microscopic system and scanning electron microscope, we found most of the adhesive layer displayed cohesive failures and that the interface failures occurred in a small part of the adhesive layer.

(2) Based on the bilinear constitutive relation of the cohesive force element, the failure process of the joint was simulated and the numerical simulation results agreed well with the experimental results. The stress distribution and progressive damage of the adhesive layer were provided. The failure load of the joint decreased with the increase in temperature. The change in shear stress of the adhesive layer with the lap length of the joint was obtained.

Author Contributions: Conceptualization, Y.Z., Z.Z., and Z.T.; data curation, Y.Z. and Z.Z.; formal analysis, Y.Z.; funding acquisition, Z.Z.; investigation, Y.Z.; methodology, Y.Z. and Z.Z.; project administration, Z.Z. and Z.T.; resources, Z.Z. and Z.T.; software, Y.Z.; validation, Y.Z.; writing一original draft, Y.Z.; writing一review \& editing, Y.Z. and Z.Z.

Funding: This work was supported by the National Natural Science Foundation of China under Grant No. 11572101.

Acknowledgments: In this study, the supplier of all materials and parameters was China Academy of Launch Vehicle Technology. The data in Table 1 were obtained from the non-notched tensile, compressive, and shear tests of $\mathrm{C} / \mathrm{C}$ composites carried out by the staff of the organization at different temperatures, respectively. The data in Table 3 were measured a tensile test of the stick-shaped butt joint and a high-temperature alloy single lap 
joint tensile shear test. The data in Table 4 were obtained by a tension test of $\mathrm{C} / \mathrm{C}$ double cantilever beams with prefabricated cracks and a three-point bending test for $\mathrm{C} / \mathrm{C}$ beams with prefabricated cracks.

Conflicts of Interest: The authors declare no conflict of interest.

\section{References}

1. Banea, M.D.; Da Silva, L.F.M. Adhesively bonded joints in composite materials: An overview. Proc. Inst. Mech. Eng. Part L 2009, 223, 1-18. [CrossRef]

2. Budhe, S.; Banea, M.D.; De Barros, S.; Da Silva, L.F.M. An updated review of adhesively bonded joints in composite materials. Int. J. Adhes. Adhes. 2017, 72, 30-42. [CrossRef]

3. Ozel, A.; Yazici, B.; Akpinar, S.; Aydin, M.D.; Temiz, S. A study on the strength of adhesively bonded joints with different adherends. Compos. Part B Eng. 2014, 62, 167-174. [CrossRef]

4. Tang, J.H.; Sridhar, I.; Srikanth, N. Static and fatigue failure analysis of adhesively bonded thick composite single lap joints. Compos. Sci. Technol. 2013, 86, 18-25.

5. Smith, L.M.; Rogers, C.W. Bonded Bomber-B-58. SAE Trans. 1962, 70, 477-486.

6. Gray, P.J.; O'Higgins, R.M.; McCarthy, C.T. Effect of thickness and laminate taper on the stiffness, strength and secondary bending of single-lap, single-bolt countersunk composite joints. Compos. Struct. 2014, 107, 315-324. [CrossRef]

7. Li, J.F.; Yan, Y.; Liang, Z.D.; Zhang, T.T. Experimental and numerical study of.adhesively bonded CFRP scarf-lap joints subjected to tensile loads. J. Adhes. 2016, 92, 1-17. [CrossRef]

8. Akhavan-Safar, A.; Ayatollahi, M.R.; Da Silva, L.F.M. Strength prediction of adhesively bonded single lap joints with different bondline thicknesses: A critical longitudinal strain approach. Int. J. Solids Struct. 2017, 109, 189-198. [CrossRef]

9. Lang, T.P.; Mallick, P.K. The effect of recessing on the stresses in adhesively bonded single-lap joints. Int. J. Adhes. Adhes. 1999, 19, 257-271. [CrossRef]

10. Hu, P.; Han, X.; Li, W.D.; Li, L.; Shao, Q. Research on the static strength performance of adhesive single lap joints subjected to extreme temperature environment for automotive industry. Int. J. Adhes. Adhes. 2013, 41, 119-126. [CrossRef]

11. Grant, L.D.R.; Adams, R.D.; Da Silva, L.F.M. Effect of the temperature on the strength of adhesively bonded single lap and $\mathrm{T}$ joints for the automotive industry. Int. J. Adhes. Adhes. 2009, 29, 535-542. [CrossRef]

12. Arikan, V.; Dogan, A.; Dogan, T.; Sabanci, E.; Kadum, A.; Al-Shamary, J. Effects of temperature and hole drilling on adhesively bonded single-lap joints. J. Adhes. 2015, 91, 177-185. [CrossRef]

13. Liao, L.J.; Kobayashi, T.; Sawa, T.; Goda, Y. 3-D FEM stress analysis and strength evaluation of single-lap adhesive joints subjected to impact tensile loads. Int. J. Adhes. Adhes. 2011, 31, 612-619. [CrossRef]

14. Khalili, S.M.R.; Mokhtari, M. Numerical study of adhesive single-lap joints with composite adherends subjected to combined tension-torsion Loads. J. Adhes. 2015, 91, 214-234. [CrossRef]

15. Carsi, M.; Sanchis, M.J.; Gómez, C.M.; Rodriguez, S.; Torres, F.G. Effect of Chitin Whiskers on the Molecular Dynamics of Carrageenan-Based Nanocomposites. Polymers 2019, 11, 1083. [CrossRef]

16. Yin, S.; Cizek, J.; Chen, C.; Jenkins, R.; O’Donnell, G.; Lupoi, R. Metallurgical bonding between metal matrix and core-shelled reinforcements in cold sprayed composite coating. Scr. Mater. 2020, 177, 49-53. [CrossRef]

17. Yamagata, Y.; Lu, X.; Sekiguchi, Y.; Sato, C. Experimental investigation of mode I fracture energy of adhesively bonded joints under impact loading conditions. Appl. Adhes. Sci. 2017, 5, 1-10. [CrossRef]

18. Li, G.; Lee-Sullivan, P. Finite element and experimental studies on single-lap balanced joints in tension. Int. J. Adhes. Adhes. 2001, 21, 211-220. [CrossRef]

19. Owens, J.F.P.; Lee-Sullivan, P. Stiffness behaviour due to fracture in adhesively bonded composite-to-aluminum joints II. Experimental. Int. J. Adhes. Adhes. 2000, 20, 47-58. [CrossRef]

20. Anyfantis, K.N.; Tsouvalis, N.G. Loading and fracture response of CFRP-to-steel adhesively bonded joints with thick adherents-Part II: Numerical simulation. Compos. Struct. 2013, 96, 858-868. [CrossRef]

21. Ribeiro, F.L.; Borges, L.; D'Almeida, J.R.M. Numerical stress analysis of carbon-fibre-reinforced epoxy composite single-lap joints. Int. J. Adhes. Adhes. 2011, 31, 331-337. [CrossRef]

22. Her, S.C. Stress analysis of adhesively-bonded lap joints. Compos. Struct. 1999, 47, 673-678. [CrossRef]

23. Bruneton, E.; Narcy, B.; Oberlin, A. Carbon-carbon composites prepared by a rapid densification process I: Synthesis and physico-chemical data. Carbon 1997, 35, 1593-1598. [CrossRef] 
24. Westwood, M.E.; Webster, J.D.; Day, R.J.; Hayes, F.H.; Taylor, R. Oxidation protection for carbon fibre composites. J. Mater. Sci. 1996, 31, 1389-1397. [CrossRef]

25. Fang, H.T.; Zhu, J.C.; Yin, Z.D. A Si-Mo fused slurry coating for oxidation protection of carbon-carbon composites. J. Mater. Sci. 2001, 20, 175-177.

26. Golecki, I.; Morris, R.C.; Narasimhan, D.; Clements, N. Rapid densification of porous carbon-carbon composites by thermal-gradient chemical vapor infiltration. Appl. Phys. Lett. 1995, 66, 2334-2336. [CrossRef]

27. Delhaes, P.; Trinquecoste, M.; Lines, J.F.; Cosculluela, A.; Goyheneche, J.M.; Couzi, M. Chemical vapor infiltration of C/C composites: Fast densification processes and matrix characterizations. Carbon 2005, 43, 681-691. [CrossRef]

28. Delhaes, P. Chemical vapor deposition and infiltration processes of carbon materials. Carbon 2002, 40, 641-657. [CrossRef]

29. ASTM C 1292. Standard Test Method for Shear Strength of Continuous Fiber-Reinforced Advanced Ceramics at Ambient Temperatures; ASTM International: West Conshohocken, PA, USA, 2010.

30. Serrano, E. A numerical study of the shear-strength-predicting capabilities of test specimens for wood-adhesive bonds. Int. J. Adhes. Adhes. 2004, 24, 23-35. [CrossRef]

31. Ferraris, M.; Ventrella, A.; Salvo, M.; Avalle, M.; Pavia, F.; Martin, E. Comparison of shear strength tests on AV119 epoxy-joined carbon/carbon composites. Compos. Part B Eng. 2010, 41, 182-191. [CrossRef]

32. Feraren, P.; Jensen, H.M. Cohesive zone modelling of interface fracture near flaws in adhesive joints. Eng. Fract. Mech. 2004, 71, 2125-2142. [CrossRef]

33. Ridha, M.; Tan, V.B.C.; Tay, T.E. Traction-separation laws for progressive failure of bonded scarf repair of composite panel. Compos. Struct. 2011, 93, 1239-1245. [CrossRef]

34. Da Silva, L.F.M.; Adams, R.D. Adhesive joints at high and low temperatures using similar and dissimilar adherends and dual adhesives. Int. J. Adhes. Adhes. 2007, 27, 216-226. [CrossRef]

35. Li, S.; Chen, X.; Chen, F. The effect of high temperature heat-treatment on the strength of $\mathrm{C} / \mathrm{C}$ to $\mathrm{C} / \mathrm{C}-\mathrm{SiC}$ joints. Carbon 2010, 48, 3042-3049. [CrossRef]

(C) 2019 by the authors. Licensee MDPI, Basel, Switzerland. This article is an open access article distributed under the terms and conditions of the Creative Commons Attribution (CC BY) license (http://creativecommons.org/licenses/by/4.0/). 